Caligrama, Belo Horizonte, v. 23, n. 2, p. 99-120, 2018

\title{
A concordância nominal no português brasileiro falado em Nova Iguaçu
}

\section{Nominal agreements in the Brazilian Portuguese spoken in Nova Iguaçu}

\section{Letícia Alves Moreira}

Universidade Federal Rural do Rio de Janeiro, Seropédica, Rio de Janeiro / Brasil leticia._alvees@hotmail.com

Juliana Segadas Vianna

Universidade Federal Rural do Rio de Janeiro, Seropédica, Rio de Janeiro / Brasil jusegadas@gmail.com

Resumo: O objetivo deste artigo é analisar a concordância nominal de número de terceira pessoa do plural em uma variedade urbana do português do Brasil, com base na fala de 12 indivíduos naturais de Nova Iguaçu, com níveis fundamental, médio e superior de instrução, distribuídos, ainda, por duas faixas etárias e sexo. Com o objetivo de descrever essa variedade, o trabalho avalia as motivações de natureza estrutural e social segundo os pressupostos da Teoria da Variação e Mudança (WEINREICH; LABOV; HERZOG, 1968). Para tanto, o ponto de partida da investigação são os resultados apresentados por Brandão (2011, 2013), Brandão e Vieira (2012a, 2012b) e Vieira e Brandão (2014). Nossos resultados parecem apontar a grande influência das motivações sociais para o fenômeno variável nos dias de hoje.

Palavras-chave: concordância de número; sintagma nominal; variação linguística.

Abstract: The purpose of this paper is to analyze the nominal agreement of the third person plural in an urban variety of Brazilian Portuguese. The sample group consisted of 12 individuals from Nova Iguaçu, with primary, secondary and university education levels, who were then also categorized by age and sex. In order to describe this variation, structural and social motivations have been evaluated through the lens of the Theory of Variation and Change (WEINREICH; LABOV; HERZOG, 1968). Therefore, the 
starting point of the research is the results presented by Brandão (2011, 2013), Brandão and Vieira (2012a, 2012b) and Vieira and Brandão (2014). Our results seem to point to the great influence of social motivations on this contemporary variable phenomenon.

Keywords: nominal number agreement; noun phrase; linguistic variation.

\section{Introdução}

A importância atribuída ao estudo da concordância de número no sintagma nominal (SN) tem instigado pesquisadores de diferentes linhas teóricas, durante os últimos quarenta anos. Um dos motivos de tamanho interesse reside no fato de que é justamente este fenômeno morfossintático o que, aparentemente, mais opõe contrastes quando se comparam as variedades brasileira e europeia da língua. Enquanto se observa riqueza flexional, havendo concordância nominal (praticamente) categórica no português europeu (PE), o português do Brasil (PB) caracteriza-se pela perda de morfologia flexional e de regras de concordância.

No que se refere à descrição do fenômeno para o PB, sobretudo na perspectiva da Sociolinguística laboviana, já existem trabalhos bastante completos que buscam decifrar quais condicionamentos sociais e/ou linguísticos impulsionam a variação nas estratégias de concordância nominal (BRANDÃO; ALMEIDA, 1999; BRAGA; SCHERRE, 1976; BRAGA, 1977; SCHERRE, 1978, 1988, 1994; BRANDÃO, 2011, 2013; BRANDÃO; VIEIRA, 2012a, 2012b; VIEIRA; BRANDÃO, 2014).

Partindo destes resultados, propõe-se a investigação da concordância de número, no âmbito do sintagma nominal, com base em um corpus ainda não analisado, que conta com entrevistas orais coletadas entre informantes em Nova Iguaçu, entre 2015 e 2017. Assim sendo, intenciona-se analisar a variação nas estratégias de concordância nominal com base em informantes cultos e não-cultos, de modo a compreender em que medida e de que maneira a mudança linguística se processa no município, em comparação com o restante do estado. 


\section{Justificativa: o que ainda falta investigar sobre o fenômeno?}

No que diz respeito à proposta de investigação, vale observar os resultados encontrados em Brandão (2011), com base em uma amostra de língua oral coletada entre os anos de 2008 e 2009, no município de Nova Iguaçu.

Tal investigação parte do controle de variáveis linguísticas e sociais, das quais se destacaram, em ordem de importância: (1) posição linear e relativa dos constituintes no $S N$; (2) escolarização do informante; (3) faixa etária; (4) saliência fônica; (5) animacidade do núcleo. Veja-se cada um deles ${ }^{1}$, começando pelos grupos de fatores sociais e passando, posteriormente, para análise das variáveis linguísticas.

Com relação à variável que controla a escolarização do informante, a autora verifica que os indivíduos de escolaridade fundamental (PR $0.62^{2}$ ) e média (PR 0.76) tendem a um maior cancelamento de marcas, em oposição aos indivíduos mais escolarizados, isto é, com frequência universitária ( $P R$ 0.26). Além disso, no que diz respeito às faixas etárias controladas, verificou-se que são os indivíduos mais velhos os mais predispostos ao cancelamento de marcas (PR 0.64). Por outro lado, os mais jovens e os adultos de meia-idade tendem a adotar um comportamento mais próximo à norma, com índices bastante próximos, respectivamente: PR 0.48 e 0.41 .

Em relação aos grupos de fatores linguísticos, o controle da posição linear e relativa dos constituintes no interior do $\mathrm{SN}$ mostrou que itens que ocupam a primeira posição, ou seja, que estão à esquerda, apresentam uma tendência maior para a retenção dos morfemas de número (PR 0.17) do que os itens situados da segunda posição em diante. Quanto mais à direita no sintagma, maior é a tendência de apagamento das marcas de número.

Com relação ao controle do nível de saliência fônica, os resultados demonstram que itens menos marcados do ponto de vista fônico tem uma maior possibilidade de apresentar cancelamento do morfema de número (PR 0.52) que os itens mais marcados (PR 0.30). Por fim, o controle da animacidade do núcleo demonstra que vocábulos com o traço [+ animado], em que predomina o traço [+ humano], são menos sujeitos ao apagamento das marcas de número (PR 0.43) do que os de traços [- animado] (PR 0.55).

\footnotetext{
${ }^{1} \mathrm{O}$ fator de aplicação é cancelamento da marca de número.

${ }^{2}$ São reproduzidos os resultados em peso relativo (PR), discutidos em Brandão (2011).
} 
Como se pode constatar, os resultados de Brandão (2011) mostram-se bastante interessantes para a compreensão do fenômeno variável, ainda que baseados em uma amostra com apenas 18 informantes. Na presente investigação, propõe-se a ampliação desta amostragem com a análise de 12 outros informantes nativos de Nova Iguaçu, coletadas entre 2015 e 2017. A comparação dos resultados também poderá dar indícios sobre o comportamento da comunidade na curta duração (LABOV, 1994; PAIVA; DUARTE, 2003).

\section{Pressupostos teórico-metodológicos}

Visto que o objetivo do trabalho é investigar a variação nas estratégias de concordância no interior do sintagma nominal, mostrase pertinente a adoção dos pressupostos teórico-metodológicos da Sociolinguística de base laboviana (LABOV, 1994; WEINREICH; LABOV; HERZOG, 1968, 2006). Partindo de tal perspectiva, foram levantados os dados linguísticos em estudo, com base em entrevistas orais coletadas entre 12 informantes do município de Nova Iguaçu, previamente transcritas e digitalizadas. Abaixo, apresentam-se as informações sumárias dos sujeitos entrevistados cujas falas foram analisadas para a presente investigação:

Quadro 1 - Informações acerca dos perfis dos entrevistados cuja fala foi analisada

\begin{tabular}{ll|l|l|l}
\hline Identificador & Sexo & Idade & Grupo etário & Escolaridade \\
\hline Inf.1 & Feminino & 32 & Jovem adulto & Fundamental \\
Inf.2 & Masculino & 18 & Jovem adulto & Fundamental \\
Inf.3 & Feminino & 28 & Jovem adulto & Médio \\
Inf.4 & Masculino & 24 & Jovem adulto & Médio \\
Inf.5 & Feminino & 23 & Jovem adulto & Superior \\
Inf.6 & Masculino & 26 & Jovem adulto & Superior \\
Inf.7 & Feminino & 64 & Idoso & Fundamental \\
Inf.8 & Masculino & 68 & Idoso & Fundamental \\
Inf.9 & Feminino & 56 & Idoso & Médio \\
Inf.10 & Masculino & 56 & Idoso & Médio \\
Inf.11 & Feminino & 66 & Idoso & Superior \\
Inf.12 & Masculino & 61 & Idoso & Superior \\
\hline
\end{tabular}


O município de Nova Iguaçu localiza-se no estado do Rio de Janeiro, a noroeste da capital, distando desta cerca de $28 \mathrm{~km}$. Segundo o Instituto Brasileiro de Geografia e Estatística (IBGE) (2017), é a quarta cidade mais populosa do estado (798 mil habitantes), ficando atrás apenas da capital $(6,5$ milhões), de São Gonçalo (1,04 milhão) e de Duque de Caxias (890 mil). O mapa abaixo localiza o município de Nova Iguaçu (13) em relação aos outros municípios que constituem o estado do Rio de Janeiro:

Figura 1 - Mapa da região metropolitana do Estado do Rio de Janeiro

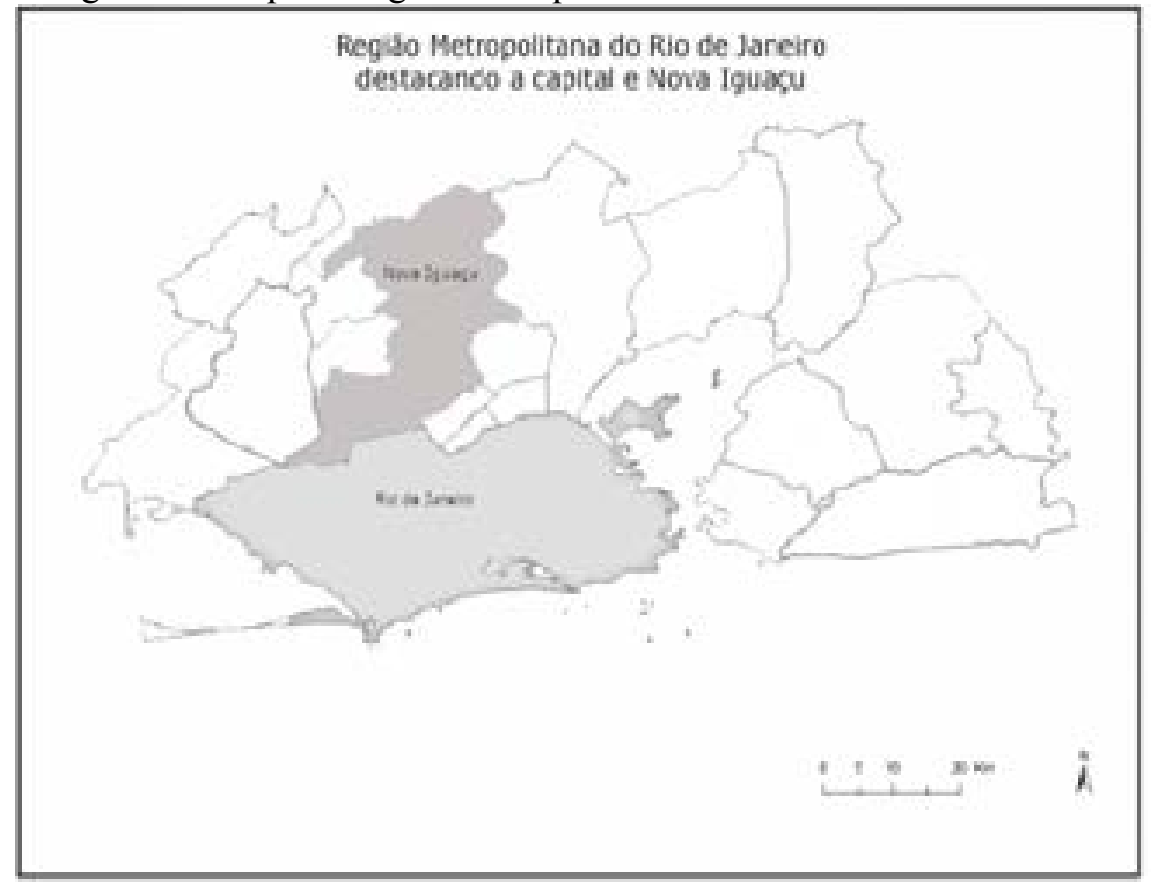

Fonte: Acervo próprio, elaborado a partir da base cartográfica do IBGE.

Nossa amostra de língua oral, organizada no âmbito do projeto de pesquisa "Nova Iguaçu sob o viés da Sociolinguística", entre os anos de 2015 e 2017, serviu de base para a investigação do fenômeno linguístico, propiciando a comparação com os resultados de Brandão (2011), a partir de entrevistas gravadas na mesma cidade, entre os anos de 2008 e 2009.

Os dados levantados foram codificados de acordo com cinco fatores linguísticos (posição do termo no interior do $\mathrm{SN}$, posição do SN no interior da oração, animacidade, saliência fônica e paralelismo 
formal) e os três fatores sociais que estratificavam a amostra (gênero, faixa etária, escolaridade) e, posteriormente, submetidos ao programa estatístico de regras variáveis, denominado Goldvarb $X$. Os principais resultados encontrados pelo programa computacional serão apresentados nas seções seguintes.

\section{Resultados}

\subsection{Frequência geral das estratégias de concordância de número no âmbito do sintagma nominal}

$\mathrm{Na}$ língua portuguesa são possíveis diferentes padrões para manifestar a categoria de número no interior do sintagma nominal. A gramática tradicional prescreve que o único uso "correto" é aquele no qual a marcação de número ocorre redundantemente em todos os elementos flexionáveis, sempre em consonância com a marca presente no núcleo nominal. $\mathrm{O}$ exemplo a seguir ilustra o uso prescrito pelas gramáticas e que recebe o maior grau de prestígio social no PB:

(1) [Todos aqueles seus primos angolanos] vieram visitá-lo em janeiro.

Como se pode observar, o núcleo nominal "primos", exibindo a marca de plural "-s", determinaria 'em tese' a concordância de todos os termos a ele subordinados, como é o caso do quantificador "todos", do demonstrativo "aqueles", do possessivo "seus" e do adjetivo "angolanos". Na fala, no entanto, estruturas desse tipo não são a única possibilidade da língua, e é possível a ocorrência de outros padrões, podendo ser parcialmente marcados, ou mesmo marcados em apenas um dos seus constituintes.

(2) [Aquelas blusinha_]

(3) [Os meus filho_]

(4) [As primeira_mudança_]

(5) [Esses carioca_malhado_]

Além disso, sintagmas nominais constituídos de cinco elementos são menos comuns no português, em comparação aos de dois ou três elementos, muito mais frequentes, como se vê na Tabela 1. 
Tabela 1 - Número de SNs por posição de núcleos

\begin{tabular}{l|c|c}
\hline \multicolumn{1}{c|}{ Posição do núcleo no $S N$} & Número / Total & Perc. \\
\hline $1^{\text {a }}$ posição & $90 / 1129$ & $8 \%$ \\
$2^{\text {a }}$ posição & $917 / 1129$ & $81 \%$ \\
$3^{\text {a }} / 4^{\text {a }}$ posição & $122 / 1129$ & $11 \%$ \\
\hline
\end{tabular}

Dos 1129 sintagmas nominais localizados em nossa amostra, foi possível observar que a grande maioria deles apresentava estrutura com núcleo na segunda posição $(81 \%)$. Com base em tais dados, localizouse a produtividade geral das estratégias de concordância de número no interior dos SNs, independentemente do número de elementos ou da posição do núcleo em seu interior. A Tabela 2 ilustra os resultados gerais da frequência de retenção e apagamento da marca de plural:

\begin{tabular}{cc}
\multicolumn{2}{c}{ Tabela 2 - Frequência geral da marcação de número no SN } \\
\hline Presença de marca de número & Ausência de marca de número \\
\hline $2.535 / 2655$ & $120 / 2655$ \\
$95 \%$ & $5 \%$ \\
\hline
\end{tabular}

De acordo com os resultados, constatou-se que na língua oral a retenção da marca de número é bastante produtiva em dados de Nova Iguaçu. Em um total de 2655 itens flexionáveis, localizaram-se 2535 ocorrências em que a marca de plural encontrava-se explícita (95\%), contra apenas 120 casos de apagamento da marca de número (5\%). Tal resultado, em princípio, referenda os altos índices de concordância nominal explícita no $\mathrm{PB}$, à semelhança do que outras pesquisas anteriores constataram, notadamente os resultados de Brandão (2011, 2013), Brandão e Vieira (2012a, 2012b) e Vieira e Brandão (2014).

Todavia, também se verifica um diferencial em relação a outras pesquisas, principalmente no que se refere à tipologia de regras linguísticas ${ }^{3}$ que melhor caracterizaria o fenômeno sob análise (LABOV, 2003): enquanto outras investigações caracterizam o fenômeno da

\footnotetext{
${ }^{3}$ De acordo com as tipologias propostas em Labov (2003) e esquematizadas em Vieira e Brandão (2014), pode-se categorizar as regras linguísticas em três tipos: (a) categórico, aquele que opera com 100\% de frequência, não ocorrendo variação; (b) semicategórico, aquele que ocorre em entre $95 \%$ a $99 \%$ dos casos, com raras exceções em que se verifica variação; e (c) variável, que ocorre em entre 5\% a 95\% dos casos.
} 
marcação do número no $\mathrm{SN}$ como sendo variável no $\mathrm{PB}$; em nossa amostra, os dados apontam para uma regra semicategórica.

\subsection{Os grupos de fatores selecionados para a variação na concordância nominal entre informantes de Nova Iguaçu}

Entre os grupos de fatores linguísticos e extralinguísticos controlados, seis foram apontados como relevantes na variação da concordância nominal para Nova Iguaçu, na seguinte ordem:

$1^{\circ}$ ) escolaridade;

$2^{\circ}$ ) posição do termo no interior do $\mathrm{SN}$;

$3^{\circ}$ ) faixa etária;

$4^{\circ}$ ) gênero;

$5^{\circ}$ ) localização do SN no interior da oração.

Tendo em vista tal resultado, pode-se dizer que chama a atenção a elevada importância das restrições extralinguísticas para o fenômeno variável, principalmente se tivermos em perspectiva que todos os grupos de fatores sociais foram selecionados, praticamente, nas primeiras posições.

Em função da destacada importância que os fatores sociais parecem assumir para o fenômeno em questão, a apresentação e análise de tais grupos será feita antes da apresentação dos grupos linguísticos selecionados pelo programa computacional de regras variáveis.

\subsubsection{Escolaridade}

A escolaridade foi o primeiro grupo de fatores selecionado pelo Programa Goldvarb X. Foram controlados três níveis de escolarização para os informantes de Nova Iguaçu, a saber: (i) ensino fundamental; (ii) ensino médio; e (iii) ensino superior. A Tabela 3 sintetiza os resultados encontrados: 
Tabela 3 - Manutenção de marcas de plural no interior do SN

\begin{tabular}{ccc}
\hline Fator & Frequência & Peso relativo \\
\hline Ensino fundamental & $576 / 657$ & 0.08 \\
& $87 \%$ & 0.18 \\
Ensino médio & $656 / 692$ & \\
& $94 \%$ & 0.90 \\
Ensino superior & $1117 / 1119$ & \\
\hline
\end{tabular}

De acordo com a Tabela 3, observa-se que, no ensino fundamental - o nível mais baixo de escolaridade controlado na amostra -, foram localizados 576 dados de presença de marca em 657 ocorrências totais, ou seja, 87\%. Embora a produtividade da marcação de plural não seja tão baixa, o peso relativo encontrado para o fator (apenas 0.08 ) indica-o como extremamente desfavorecedor para retenção da marca de plural no SN.

$\mathrm{Na}$ escolarização intermediária (equivalente ao ensino médio), por sua vez, foram identificados 656 dados de retenção de marca de plural em um total de 692 ocorrências, registrando maior produtividade da marcação (94\%), quando comparada ao nível mais baixo de escolaridade. Todavia, semelhantemente ao observado para o nível mais básico de escolarização, o peso relativo para o fator também é baixíssimo: 0.18 . Em síntese, no caso desses dois níveis de escolaridade, os pesos relativos indicam um grande desfavorecimento no sentido da retenção de marcas de plural.

Sob outra perspectiva, em sentido inverso, o ensino universitário exibiu a maior frequência de uso: em um total de 1119 ocorrências, 1117 delas exibiam a marca de plural explícita, equivalendo a 99\% de produtividade. Pode-se dizer então que, em nossa amostra, para o nível mais alto de escolarização, o uso da concordância nominal foi praticamente categórico. $\mathrm{O}$ peso relativo encontrado para o fator referenda essa constatação: 0.90 .

Dessa forma, os resultados acima asseveram que o nível de escolaridade do falante está diretamente ligado ao fenômeno linguístico em análise, impulsionando a escolha entre a manutenção ou o apagamento de marca de plural no SN (BRANDÃO, 2011, 2013; BRANDÃO; VIEIRA, 2012a, 2012b; SCHERRE; NARO, 1998; VIEIRA; BRANDÃO, 2014). A título de comparação, vale a pena retomar os resultados de Brandão (2013 apud VIEIRA; BRANDÃO, 2014), que comparam a influência da 
escolarização em dois municípios no estado do Rio de Janeiro: a capital ${ }^{4}$ e Nova Iguaçu. Com base nesses dados, a autora afirma que "a regra de concordância no PB é semicategórica entre os indivíduos de nível superior $(97,2 \%)$ e variável na fala dos menos escolarizados" (VIEIRA; BRANDÃO, 2014, p. 91).

\subsubsection{Faixa etária}

A faixa etária foi o terceiro grupo de fatores indicado pelo programa computacional de regras variáveis na seleção geral, e o segundo grupo entre os fatores sociais controlados na pesquisa. Foram controladas duas faixas etárias para a presente investigação: indivíduos de 18 a 35 anos, representando os jovens adultos, e indivíduos de 56 a 75 anos, representando o grupo de idosos. A tabela a seguir ilustra os resultados encontrados na amostra de Nova Iguaçu:

Tabela 4 - Manutenção de marca de plural no interior do SN conforme a faixa etária

\begin{tabular}{c|c|c}
\hline Fator & Frequência & Peso relativo \\
\hline 18 a 35 anos & $1388 / 1428$ & 0.66 \\
& $97 \%$ & \\
& $961 / 1040$ & 0.28 \\
56 a 75 anos & $92 \%$ & \\
\hline
\end{tabular}

De acordo com a Tabela 3, observa-se que, entre os jovens adultos (de 18 a 35 anos), dos 1428 dados localizados, 1388 atestavam a presença de marcas de pluralidade no interior do SN, ou seja, em 97\% dos casos. Por outro lado, entre informantes mais idosos (de 56 a 75 anos), a frequência de retenção da marca de plural é relativamente mais baixa: 92\%. Dos 1040 dados totais localizados em tal faixa etária, apenas 961 apresentam a marcação de plural explícita. Os pesos relativos encontrados para os fatores referendam os percentuais encontrados, demonstrando que a faixa etária mais nova, dos jovens adultos, favorece a manutenção das marcas de plural (PR 0.66), ao passo que a faixa etária mais idosa, da terceira idade, desfavorece a aplicação da regra (PR 0.28).

\footnotetext{
${ }^{4}$ Em Brandão (2013), a autora utiliza-se de entrevistas coletadas especificamente no bairro de Copacabana.
} 
De acordo com Scherre e Naro (1998), as faixas etárias mais novas tendem a deixar as marcas evidentes, ao mesmo tempo que os mais velhos ficam mais predispostos ao cancelamento. Ainda segundo a análise dos autores, as pessoas mais jovens buscam se apropriar dos usos linguísticos de maior valor de prestígio na sociedade, motivadas pela necessidade de inserção no mercado de trabalho. Tal conclusão também é o ponto de chegada de Brandão (2011), que assevera:

No PB, em que também a faixa etária é relevante, são os indivíduos mais velhos os mais predispostos ao cancelamento (PR.64), enquanto os mais jovens tendem a adotar a marca de concordância, com índices bastante próximos (18-35 anos: PR.48; 36-55 anos: PR.41). (BRANDÃO, 2O11, p.171)

Para maior compreensão de como se processa a interação entre escolaridade e faixa etária no comportamento do indivíduo, estabelecemos o cruzamento destes dois grupos de fatores, como pode ser observado na Tabela 5:

Tabela 5 - Manutenção de marcas de plural no interior do SN no cruzamento entre faixa etária e escolaridade

\begin{tabular}{l|c|c|c}
\hline \multirow{1}{*}{ Faixa etária } & \multicolumn{3}{|c}{ Escolaridade } \\
\cline { 2 - 4 } & Fundamental & Média & Superior \\
\hline Jovens adultos & $367 / 405$ & $441 / 441$ & $580 / 580$ \\
(18 a 35 anos) & $91 \%$ & $100 \%$ & $100 \%$ \\
Idosos & $209 / 252$ & $215 / 249$ & $537 / 539$ \\
(56 a 75 anos) & $83 \%$ & $86 \%$ & $100 \%$ \\
\hline
\end{tabular}

De acordo com os resultados encontrados na amostra, verificou-se que, independentemente da faixa etária, a escolaridade superior parece determinar a retenção da marca de plural em todos os elementos do SN. Em nossos dados, a aplicação da regra foi categórica entre informantes altamente escolarizados, independentemente de serem jovens adultos ou idosos.

As escolaridades média (EM) e fundamental (EF), por sua vez, parecem favorecer a variação entre os usos linguísticos, ora ocorrendo manutenção, ora apagamento da marca de plural. Além disso, verificase, para esses níveis de instrução, a atuação da faixa etária do indivíduo determinando se a variação será maior ou menor. Quando o informante pertence ao grupo dos jovens, há um comportamento linguístico mais conservador (com mais manutenção das marcas de plural, podendo ser 
categórico: 91\%, no EF, e 100\%, no EM); enquanto, entre os informantes idosos, o comportamento é menos conservador (exibindo-se mais variação entre os usos: $83 \%$, no EF, e $86 \%$, no EM).

Tais observações são compatíveis com o que foi constatado por Brandão (2011). Segundo a autora, a escolaridade de nível superior é um fator dominante em qualquer faixa etária que o indivíduo possa ocupar, uma vez que foi verificada uma frequência altíssima (100\%) de concordância de número no $\mathrm{SN}$, nas duas faixas etárias analisadas (18-35 anos e 56-75 anos). Levando-se em conta as escolaridades intermediárias, entretanto, observa-se nos resultados de Brandão (2011) que as faixas etárias atuam diferentemente sobre o fenômeno. Ainda que os indivíduos tenham o mesmo nível de escolaridade (médio ou fundamental), as faixas etárias diferenciam os comportamentos, visto que os mais novos mantêm a marca de pluralidade e os mais velhos são mais propensos ao apagamento.

Reafirmando tais constatações, Scherre e Naro (1998), com base em um corpus de 64 gravações de 60 minutos cada, também chegam à conclusão de que as faixas etárias são altamente influenciáveis pela idade profissionalmente produtiva dos indivíduos, já que esses necessitariam de um maior domínio em relação à norma de prestígio social.

\subsubsection{Gênero}

Outro controle que apresentou resultados significativos para o estudo da concordância nominal foi o dos gêneros que estratificavam a amostra. Embora tenha sido o último fator social apontado pelo programa Goldvarb $X$, foi o quarto grupo de fatores na seleção geral, o que demonstra sua importância para o fenômeno em estudo.

A Tabela 6 ilustra os resultados encontrados para a retenção da marca de plural, tendo em vista o gênero dos informantes de Nova Iguaçu:

Tabela 6 - Manutenção da marca de plural no interior do SN conforme o gênero

\begin{tabular}{c|c|c}
\hline Fator & Frequência & Peso relativo \\
\hline Feminino & $1109 / 1198$ & 0.34 \\
& $92 \%$ & \\
Masculino & $1240 / 1270$ & 0.64 \\
& $97 \%$ & \\
\hline
\end{tabular}

De acordo com os dados obtidos na análise das entrevistas, entre as informantes do gênero feminino, foram localizados 1109 casos de 
manutenção da marca de plural no SN, em um total de 1198 ocorrências produzidas por mulheres: $92 \%$ do total. Embora seja um resultado bastante produtivo, não chega ser uma regra semicategórica (LABOV, 2003) como observado entre os homens. Entre eles, localizaram-se 1.240 dados de presença de marca, em um universo de 1.270 ocorrências totais, ou seja, $97 \%$ de produtividade.

A observação dos pesos relativos associados aos fatores ratifica que o comportamento de homens e mulheres é diferenciado quando se tem em vista o fenômeno da marcação de plural no interior do SN. De acordo com os pesos relativos, a aplicação da regra é favorecida entre os homens (PR 0.64), e desfavorecida entre as mulheres (PR 0.34).

Curioso perceber que nosso resultado difere do de outras pesquisas realizadas anteriormente, segundo as quais as mulheres seriam mais sensíveis aos usos padrão, enquanto os homens teriam um comportamento mais despreocupado com a língua, com mais apagamentos de marcas de plural (SCHERRE; NARO, 1998; OUSHIRO, 2015). Nesse sentido, várias pesquisas apontam correlação entre o gênero feminino e a preferência por usos linguísticos da variedade padrão; enquanto as variantes consideradas não-padrão ou estigmatizadas tendem a ocorrer mais frequentemente entre os homens. Todavia, ainda que a recorrência de tal correlação seja notada, a interpretação que se dá a ela nem sempre é consensual, como aponta Oushiro (2015, p.152):

Já se sugeriu que as mulheres tendem a empregar formas de prestígio como maneira de tentar superar sua posição desprivilegiada na sociedade (FASOLD, 1990), de não se identificar simbolicamente com a promiscuidade (GORDON, 1997), de manter a face em relações nas quais não detêm o poder (DEUCHAR, 1988), ou de adquirir status social indiretamente, ao passo que os homens podem fazê-lo por meio da sua ocupação e renda (TRUDGILL, 1972).

Talvez a ampliação do número de entrevistas analisadas possa elucidar, em um próximo momento da pesquisa, as questões relativas ao comportamento de homens e mulheres na amostra Nova Iguaçu. Por hora, com o objetivo de melhor observar a influência do gênero/sexo do informante para a aplicação da regra de concordância nominal, cruzamos tal grupo de fatores com o controle da escolarização. Os resultados podem ser vistos na Tabela 7: 
Tabela 7 - Manutenção de marcas de plural no interior do SN no cruzamento gênero e escolaridade

\begin{tabular}{c|c|c|c}
\hline \multirow{2}{*}{ Gênero } & \multicolumn{3}{|c}{ Escolaridade } \\
\cline { 2 - 4 } & Fundamental & Média & Superior \\
\hline \multirow{2}{*}{ Masculino } & $279 / 287$ & $337 / 357$ & $624 / 626$ \\
& $97 \%$ & $94 \%$ & $100 \%$ \\
Feminino & $297 / 370$ & $319 / 335$ & $493 / 493$ \\
& $80 \%$ & $95 \%$ & $100 \%$ \\
\hline
\end{tabular}

De acordo com a Tabela 7, é possível verificar que, nas faixas de escolarização média e superior, os homens da amostra Nova Iguaçu têm taxas de retenção da marca de plural (praticamente) idênticas às das mulheres.

A maior diferença observada, no que se refere ao gênero, diz respeito apenas ao menor nível de escolarização. Entre informantes de escolarização fundamental, homens apresentam altas taxas de retenção da marca de plural (97\%), enquanto as mulheres apresentam maior variação de estratégias, com menor retenção da marca de plural (80\%). Os resultados não são conclusivos e carecem de maiores investigações.

\subsubsection{Posição do termo no interior do SN}

A posição dos termos no interior do $\mathrm{SN}$ foi o segundo grupo selecionado como importante condicionador para o fenômeno da concordância nominal no âmbito de $\mathrm{SN}$, sendo o primeiro entre os grupos de fatores estruturais observados.

No que se refere a tal grupo, controlaram-se sete possíveis posições que os elementos pré-nucleares, nucleares e pós-nucleares poderiam ocupar no interior do SN. Os exemplos abaixo ilustram o controle efetuado:

(A) Elementos pré-nucleares:

$\left(\mathrm{a}^{1}\right)$ de $1^{\mathrm{a}}$ posição

(6) e eu sou um dos responsáveis pelo engarrafamento (dado 17, $H 3 \mathrm{~A}$ )

(7) os próprios moradores fizeram justiça (dado 388, FC1)

( $\left.\mathrm{a}^{2}\right)$ de $2^{\mathrm{a}}$ posição

(8) pras minhas tias... (dado $868, F 3 A$ ) 
(9) pelos meus objetivos (dado 1063, H1A)

(B) Elementos nucleares:

$\left(b^{1}\right)$ de $1^{a}$ posição

(10) pessoas qualificadas pra somar com a gente... (dado 1126, $\mathrm{H} 2 \mathrm{C}$ )

(11) profissionais competentes para estarem dando (dado 2340, M3C)

$\left(b^{2}\right)$ de $2^{\mathrm{a}}$ posição

(12) os casado... prá cá só veio mesmo os seis. (dado 1394, HC1)

(13) os pontos positivos é que é uma cidade (dado 1517, HC3)

$\left(b^{3}\right)$ de $3^{a}$ posição em diante

(14) quando tem os nossos filho (dado 1953, MA1)

(15) as minhas filha era pequena (dado 2143, MC2)

(C) Elemento pós-nuclear:

$\left(c^{1}\right)$ de $2^{a}$ posição

(16) coisas essenciais pra se ter (dado 2189, HC2)

(17) filhos pequenos (dado 206, H3A)

$\left(\mathrm{c}^{2}\right)$ de $3^{\mathrm{a}}$ posição em diante

(18) os professores sozinhos não vão dar conta disso... (dado 2341, MC3)

(19) acho que é um dos pontos positivos (dado 2489, HA2)

Como elementos pré-nucleares na primeira e segunda posição do sintagma nominal, podem-se encontrar artigos, quantificadores e qualificadores, como em "os meus ex-alunos...", no qual "os" seria um determinante na primeira posição, e "meus", um determinante de segunda.

Os núcleos, por sua vez, figuram em diversos lugares no SN, podendo ser a posição 1, como no exemplo "pais alcoólatras"; a posição 2, em "os outros"; e a posição 3, em construções como "as suas particularidades". No que se refere aos elementos pós-nucleares, são 
encontrados itens a partir da segunda ("políticos despreparados"). Entre os falantes do português brasileiro, essas são as posições preferenciais para o uso de qualificadores ou quantificadores.

A tabela a seguir apresenta as frequências e os pesos relativos para a aplicação da regra, tendo em vista o controle da posição do termo no interior do $\mathrm{SN}$ :

Tabela 8 - Manutenção da marca de plural conforme a posição do termo no interior do SN

\begin{tabular}{|c|c|c|}
\hline Fator & Frequência & Peso relativo \\
\hline Elemento pré-nuclear de $1^{\mathrm{a}}$ posição & $\begin{array}{c}974 / 981 \\
99 \%\end{array}$ & 0.83 \\
\hline Elemento pré-nuclear de $2^{\mathrm{a}}$ posição & $\begin{array}{c}132 / 135 \\
97 \%\end{array}$ & 0.50 \\
\hline Núcleo de $1^{\mathrm{a}}$ posição & $\begin{array}{c}89 / 90 \\
98 \%\end{array}$ & 0.45 \\
\hline Núcleo de $2^{\mathrm{a}}$ posição & $\begin{array}{c}832 / 917 \\
90 \%\end{array}$ & 0.20 \\
\hline Núcleo de $3^{\mathrm{a}}$ posição em diante & $\begin{array}{c}115 / 122 \\
94 \%\end{array}$ & 0.24 \\
\hline Elemento pós-nuclear de $2^{\mathrm{a}}$ posição & $\begin{array}{l}87 / 88 \\
98 \%\end{array}$ & 0.54 \\
\hline $\begin{array}{l}\text { Elemento pós-nuclear de } 3^{\mathrm{a}} \text { posição } \\
\text { em diante }\end{array}$ & $\begin{array}{c}118 / 133 \\
88 \%\end{array}$ & 0.14 \\
\hline
\end{tabular}

Pelo que os dados do presente estudo demonstram, os elementos pré-nucleares apresentam uma produtividade superior em relação aos outros elementos nas outras posições do sintagma nominal. Como fica claro na Tabela 8 , entre os elementos pré-nucleares de $1^{\mathrm{a}}$ posição, foram localizados 974 dados de marcação explícita de plural, em um total de 981 ocorrências (99\%). O peso relativo para o fator ilustra o alto grau de favorecimento da retenção de marcas: PR 0.83. Na posição 2, ainda que seja alta a produtividade da marcação de plural (97\%) nos elementos pré-nucleares, um peso relativo mostra-se neutro (PR: 0.50). 
No que se refere aos núcleos, observa-se que os de $1^{\text {a }}$ posição apresentam mais marcas de pluralidade (98\%) do que os núcleos de $2^{\mathrm{a}} \mathrm{e}$ $3^{\text {a }}$ posição: $90 \%$ e $94 \%$, respectivamente. Tais resultados demonstram o que já se esperava, reafirmando o observado em relação às posições prénucleares. Ora, os núcleos de $2^{\mathrm{a}}$ e de $3^{\mathrm{a}}$ posição são sempre precedidos por elementos pré-nucleares de $1^{\mathrm{a}}$ posição (mais produtivos na língua), que, na maioria das vezes, já apresentam marcas de plural explicitadas. Assim, a retenção de marca de plural no núcleo torna-se redundante, haja vista que já ocorre a marcação no determinante. O peso relativo para os fatores ilustra que é baixa a retenção de marca de plural em núcleos de $2^{\mathrm{a}}$ posição (PR 0.20) e de $3^{\mathrm{a}}$ posição (PR 0.24).

Por fim, na Tabela 8 , pode-se notar que os elementos flexionáveis pospostos ao núcleo tendem a reter mais marcas de plural quanto mais perto estiverem dele (e se não houver elementos pré-nucleares no sintagma). Elementos pós-nucleares de $2^{\mathrm{a}}$ posição são mais favoráveis à retenção de marca (PR 0.54) do que os de $3^{\mathrm{a}}$ posição (PR 0.14).

Referendando os resultados encontrados na amostra, Scherre (1994) afirma que os elementos posicionados à esquerda do núcleo tendem à retenção de marca, assim como os núcleos que ocupam a $1^{\text {a }}$ posição estão sujeitos à maior marcação explícita de pluralidade (uns filho garanhão/as coisa certa/ municípios vizinhos/instituiçães falidas). Por conseguinte, os elementos que figuram na segunda posição estão mais suscetíveis ao cancelamento (meus filho/ os casado), principalmente o que se apresenta como núcleo do SN. A propósito, os elementos nucleares da terceira posição em diante são um pouco mais propícios a exibir a marca (dos nossos governantes/ todos os nossos alunos/ os meus amigos). Brandão (2011), em um artigo que focaliza os falantes de Nova Iguaçu entrevistados entre os anos de 2008 e 2009, apresenta os mesmos resultados encontrados com relação às diferentes posições no interior do SN.

Resumidamente, tendo-se em vista os elementos pós-nucleares, pode-se conjecturar que os que se estabelecem na segunda posição do SN apresentam mais marcas de pluralidade (notas falsas/ serviços gerais) que os de terceira posição (os bandido todinho/ os colega iniciante).

Os resultados acima refletem mais ainda a percepção de que os determinantes à esquerda tendem a receber mais marcas de plural, ao passo que, para os elementos à direita do $\mathrm{SN}$, ocorre o apagamento de marcas flexionáveis. Ampliando essa percepção, fica evidenciado que os 
núcleos na primeira posição também se estabelecem com mais marcas explícitas de plural que os de segunda posição. Curiosamente, os elementos nucleares da terceira posição em diante estão um pouco menos propensos ao cancelamento de marca, o que precisa de uma maior compreensão.

\subsubsection{Localização do SN em relação ao "verbo"}

Pela hipótese inicial do grupo de fatores que controlou a localização do SN na oração, entende-se que os sintagmas que se encontram à esquerda do verbo estão mais propensos a receber a marca de pluralidade do que os que estão à direita do verbo (SCHERRE, 1994). Buscando um melhor entendimento do fenômeno sob observação e considerando o sintagma inteiro como foco de análise, localizaram-se as seguintes possibilidades na amostra:

(A) Localização à esquerda

(20) os próprios moradores fizeram justiça (dados 388 e 389 , FC1)

(21) as pessoas também acabam ficando desinteressada (dados 510 e 511, FA2)

(B) Localização à direita:

(22) ele não viu os bandido (dados 380 e 381, FC1)

(23) pra liberar as motos... (dados 727 e 728, F3A)

(C) Localização indistinta:

(24) só os locais assim eh... (dados 492 e 493, FA2)

(25)... as pessoas... elas... se acomodam (dados 804 e 805, F3A) 
Tabela 9 - Manutenção da marca de plural no interior do SN, conforme a localização do SN no interior da oração

\begin{tabular}{l|c|c}
\hline \multicolumn{1}{c|}{ Fator } & Frequência & Peso relativo \\
\hline À esquerda da oração & $738 / 764$ & 0.63 \\
& $96 \%$ & \\
\multirow{2}{*}{ À direita da oração } & $1424 / 1511$ & 0.39 \\
& $94 \%$ & \\
Indistinta & $373 / 380$ & 0.65 \\
& $98 \%$ & \\
\hline
\end{tabular}

$\mathrm{Na}$ Tabela 9, é possível perceber que os SNs à esquerda da oração estão mais suscetíveis à marcação de pluralidade. Em um total de 764 elementos em sintagmas à esquerda, 738 apresentavam marcas explícitas de pluralidade (96\%), relevando um peso relativo alto para o fator (0.63). Por outro lado, SNs à direita da oração receberam menos marcas de pluralidade. Ainda que a diferença em termos percentuais pareça pouco significativa (94\%), o peso relativo para o fator (PR 0.39) revela que a posição à direita da oração é bastante desfavorecedora para a aplicação da regra.

Retomando a hipótese preliminar, pode-se notar que a presente pesquisa confirma a influência da posição dos sintagmas nominais na oração na retenção ou apagamento das marcas de plural. Segundo Scherre (1994), há uma relação de favorecimento das marcas explícitas de número em elementos que estão mais influenciados pela posição à esquerda.

\section{Considerações finais}

Os resultados demonstram a alta produtividade da retenção das marcas de plural no âmbito do SN. Todos os fatores sociais mostraram-se relevantes para o fenômeno, em especial a escolaridade e a faixa etária, à semelhança do que outras pesquisas apontam (BRANDÃO, 2011, 2013; BRANDÃ̃; VIEIRA, 2012a, 2012b; SCHERRE; NARO, 1998; VIEIRA; BRANDÃO, 2014). Comprovando nossas hipóteses iniciais, pode-se dizer que a retenção de marcas de plural é uma regra semicategórica, nos termos de Labov (2003), entre indivíduos altamente escolarizados (nível universitário) e pertencentes à faixa etária dos jovens adultos (de 18-35 anos). Por outro lado, a variação aparece na fala dos indivíduos de baixa 
escolarização (fundamental e média) e pertencentes ao grupo etário dos idosos, referendando, em especial, os resultados de Brandão (2011) com amostra coletada entre os anos 2008 e 2009, no mesmo município. Entre as restrições linguísticas que foram analisadas, destaca-se a importância dos grupos de fatores que controlam a posição linear, tanto do item linguístico no interior do SN (BRANDÃO, 2011; SCHERRE, 1994), quanto do próprio $\mathrm{SN}$ em relação à oração na qual se inclui.

\section{Referências}

BRAGA, M. L. A concordância de número no sintagma nominal no Triângulo Mineiro. 1977. 88 f. Dissertação (Mestrado em Língua Portuguesa) - Pontifícia Universidade Católica, Rio de Janeiro, 1977.

BRAGA, M. L.; SCHERRE, M. M. P. A concordância de número no SN na área urbana do Rio de Janeiro. In: ENCONTRO NACIONAL DE LINGUÍSTICA, 1., 1976, Rio de Janeiro. Anais... Rio de Janeiro: PUC, 1976. p. 464-477,

BRANDÃO, S. F. Concordância nominal em duas variedades do português: convergências e divergências. Veredas, Juiz de Fora, v. 15, n. 1, p. 164-178, 2011.

BRANDÃO, S. F. Patterns of Plural Agreement within the Noun Phrase. Journal of Portuguese Linguistics, Lisboa, v. 12, n. 2, p. 51-100, 2013. doi: https://doi.org/10.5334/jpl.68

BRANDÃO, S. F.; VIEIRA, S. R. Concordância nominal e verbal: contribuições para o debate sobre o estatuto da variação em três variedades urbanas do português. ALFA: Revista de Linguística, Araraquara, SP, v. 56, n. 3, p. 1035-1064, 2012a. doi: https://doi.org/10.1590/S198157942012000300013

BRANDÃO, S. F; ALMEIDA, E. M. Ainda sobre a concordância no âmbito do sintagma nominal. In: ESTUDOS DA LINGUAGEM: RENOVAÇÃO E SÍNTESE. CONGRESSO DA ASSEL-RIO, 7., 1998, Rio de Janeiro. Anais... Rio de Janeiro: Associação de Estudos da Linguagem do Rio de Janeiro (Assel-Rio), 1999. p. 835-843.

BRANDÃO, S. F; VIEIRA, S. R. A concordância nominal e verbal no português do Brasil e no Português de São Tomé: uma abordagem sociolinguística. PAPIA - Revista Brasileira de Estudos do Contato Linguístico, São Paulo, v. 22, n. 1, p. 7-39, 2012 b. 
INSTITUTO BRASILEIRO DE GEOGRAFIA E ESTATÍSTICA. IBGE divulga as estimativas populacionais dos municípios para 2017. Agência IBGE Notícias, Rio de Janeiro, ago. 2017. Disponível em: <https:// agenciadenoticias.ibge.gov.br/2013-agencia-de-noticias/releases/16131ibge-divulga-as-estimativas-populacionais-dos-municipios-para-2017. html $>$. Acesso em: 18 jul. 2018.

LABOV, W. Principles of Linguistic Change: Internal Factors. Oxford: Blackwell, 1994.

LABOV, W. Some Sociolinguistic Principles. In: PAULSTON, C. B.; TUCKER, G. R. (Ed.). Sociolinguistics: The Essential Readings. Massachusetts: Blackwell, 2003.

OUSHIRO, L. Interação entre sexo/gênero e classe social no uso variável da concordância verbal. In: FREITAG, R. M. K.; SEVERO, C. G. (Org.). Mulheres, linguagem e poder: estudos de gênero na sociolinguística brasileira. São Paulo: Blucher, 2015. p. 151-168. doi: https://doi. org/10.5151/9788580391213-0006

PAIVA, M. C.; DUARTE, M. E. L. (Org.). Mudança linguística em tempo real. Rio de Janeiro: Contra Capa Livraria, 2003.

SCHERRE, M. M. P. A regra de concordância de número no sintagma nominal em português. 158 f. 1978. Dissertação (Mestrado em Letras) Departamento de Letras e Artes, Pontifícia Universidade Católica, Rio de Janeiro, 1978.

SCHERRE, M. M. P. Aspectos da concordância de número no português do Brasil. Revista Internacional de Lingua Portuguesa, Lisboa, v. 12, p. 37-49. dez. 1994.

SCHERRE, M. M. P. Reanálise da concordância de número em português. 1988. Tese (Doutorado em Linguística) - Faculdade de Letras, Universidade Federal do Rio de Janeiro, Rio de Janeiro, 1988.

SCHERRE, M. M. P.; NARO, A. J. Sobre a concordância de número no português falado do Brasil. In: RUFFINO, G. (Org.). Dialetologia, geolinguística, sociolinguistica: Atti del XXI Congresso Internazionale di Linguistica e Filologia Romanza. Tübingen: Centro di Studi Filologici e Linguistici Siciliani / Universitá di Palermo, Max Niemeyer Verlag, 1998. n. 5. p. 509-523. 
VIEIRA, S. R.; BRANDÃO, S. F. Tipologia de regras linguísticas e estatuto das variedades/línguas: a concordância em português. Linguística, Rio de Janeiro, v. 30, n. 2, p. 81-112, 2014.

WEINREICH, U.; LABOV, W.; HERZOG, M. I. Empirical Foundations for a Theory of Language Change. In: LEHMANN, W.; MALKIEL, Y. (Ed.). Directions for Historical Linguistics. Austin: University of Texas Press, 1968.

WEINREICH, U.; LABOV, W.; HERZOG, M. I. Fundamentos empíricos para uma teoria da mudança linguística. São Paulo: Parábola, 2006.

Recebido em: 13 de junho de 2018.

Aprovado em: 27 de julho de 2018. 